\title{
Retraction Note to: Sea level height based on big data of Internet of Things and aerobics teaching in coastal areas
}

\author{
Jingyu Shao ${ }^{1} \cdot$ Xiaopo Cheng ${ }^{1}$
}

Published online: 15 November 2021

(c) Saudi Society for Geosciences 2021

Retraction Note to: Arabian Journal of Geosciences (2021) 14: 1450 https://doi.org/10.1007/s12517-021-07748-2

The Editor-in-Chief and the Publisher have retracted this article because the content of this article is nonsensical. The peer review process was not carried out in accordance with the Publisher's peer review policy. The authors have not responded to correspondence regarding this retraction.

The original article can be found online at https://doi.org/10.1007/ s12517-021-07748-2.

Xiaopo Cheng

chengxb@ahut.edu.cn

1 Sports Department of Anhui University of Technology, Maanshan, Anhui, China 